\title{
A case of trigeminal neuralgia developing after a COVID-19 vaccination
}

\author{
Abdurrahman Kaya ${ }^{1} \mathbb{D} \cdot$ Sibel Yıldız Kaya²
}

Received: 13 September 2021 / Revised: 20 October 2021 / Accepted: 9 November 2021 / Published online: 6 December 2021

(c) Journal of NeuroVirology, Inc. 2021

\begin{abstract}
In this case, we report a patient who developed acute trigeminal neuritis after using a Pfizer-BioNtech vaccination against SARS-CoV-2. The patient was completely recovered with steroid treatment.
\end{abstract}

Keywords Trigeminal $\cdot$ COVID-19 $\cdot$ Vaccination

\section{Introduction}

COVID-19 is a viral disease, causing serious morbidity and mortality. To prevent the disease, a variety of vaccines have developed and been administered to people all over the world. Though they have a high level of efficacy and safety across all populations, many different side effects have been shown (Polack et al. 2020; Jackson et al. 2020). Previously, neurological involvements have been reported after vaccinations (Fenichel 1982). In COVID-19 vaccinations, although neurological complications including bell's palsy, GuillainBarré syndrome, transverse myelitis, and multiple sclerosis have been observed, the incidence is not well known (Wan et al. 2021; Havla et al. 2021; Khayat-Khoei et al. 2021). Herein, we report a patient with trigeminal neuritis following the vaccination, incidentally treated with steroid.

\section{Case report}

A 45-year-old female was admitted to our hospital with 3 days of facial and jaw pain, and fatigue. Sometimes, it was accompanied by toothache. Three days ago, she received the first dose of Pfizer-BioNtech vaccine against SARS$\mathrm{CoV}-2$ and the complaints were developed following the

Abdurrahman Kaya

dr.abdkaya@hotmail.com

1 Department of Infectious Disease, Istanbul Training and Research Hospital, Istanbul, Turkey

2 Department of Infectious Disease, Sungurlu State Hospital, Sungurlu, Turkey vaccination. She was in good general condition and fully cooperative. In the medical history, the patient had no chronic diseases and did not experience any serious side effects after childhood vaccinations. Additionally, other physical examinations were normal and the laboratory values were unremarkable. The features of the pain were unilateral, acute onset, and severe. It was of short duration and localized to the right of the face. Initially, they were attributed to the general side effects of the vaccination; a nonsteroid antiinflammatory drug was administered. On the treatment, she continued to experience attacks of pain and noticed it was triggering with brushing her teeth and putting on makeup. Also, she felt the pain in the lower part of her face and stated that it was arised from a focus. In the end of a month, she still had attacks of pain which significantly reduced the quality of life of the patient. In addition, the patient refused to receive the second shot because of the ongoing complaints. Due to the findings including typical features and localization of the pain and triggering by some actions, the case was considered as trigeminal neuralgia (TN 2021). Pregabalin was administered to control the pain. However, despite 4 weeks of the treatment, the pain persisted, and her attacks continued. Concurrently, the patient was consulted for toothache. Though the dental X-ray was normal, amoxicillin/clavulanic acid (daily $2 \times 1 \mathrm{~g}$ ) was given. Following the use of the first dose antibiotic, angioedema developed, and her general condition worsened. In emergency room, $80 \mathrm{mg}$ Methylprednisolon intravenously was administered. Later, the patient was discharged to home with a 7-day tapering course of steroid. With this treatment, all complaints including facial, and jaw and tooth pain were recovered. The patient has been doing well and no recurrence on regular follow-ups for 6 months. 


\section{Discussion}

Trigeminal neuralgia (TN) is rare disease which affects women more than men. The incidence is estimated to be 4 to 13 cases per 1,000,000 and gradually increases with age. Its pain typically involves the lower face and jaw. Generally, it is limited to one side of the face and can be triggered by an routine action such as brushing your teeth, eating, or the wind (www. uptodate.com). It is characterized by clinically intense, sharp, and superficial pain in the distribution of one or more branches of the fifth cranial nerve (Headache Classification Committee of the International Headache Society (IHS) The International Classification of Headache Disorders, 3rd edition 2018). Although the clinical presentation of $\mathrm{TN}$ can differ among patients, its diagnosis is mainly based on description of the facial pain. Also, TN may sometimes be confused with dental causes of pain requiring dental examination (www. uptodate.com). In this case, she has typical clinical manifestations of TN and incidentally treated with glucocorticosteroid.

In the literature, Narasimhalu et al. reported the first case of TN with cervical radiculitis following COVID-19 vaccination (Pfizer-BioNtech) (Narasimhalu et al. 2021). The patient presented with swelling and pain over the left face and neck and MRI of trigeminal nerve revealed an abnormal asymmetric thickening. In this report, initially pregabalin was administered but the pain persisted. Finally, she was treated a tapering course of oral prednisolone. Considering the clinical features and treatment strategy, the reported case is similar to our patient who is the second one in the literature. In addition, Molina-Gil et al. reported a case of COVID-19 infection presenting with TN (Molina-Gil et al. 2021).

After COVID-19 vaccinations, though neurological involvements are described, the exact mechanism is not fully elucidated and has been attributed to molecular mimicry and immune-mediated inflammatory response (Doser et al. 2002) (Narasimhalu et al. 2021). While the former often requires at least 10-14 days to develop, the latter needs less time to develop than it. In our case, we think immune-mediated inflammation is a more likely mechanism due to the fairly rapid onset of the symptoms and the response to corticosteroids.

In conclusion, neurological complications including TN can be observed in a COVID-19 vaccination. Its pain may fail to respond to traditional treatments and recur. In such cases, corticosteroids should be considered as a choice of therapy. Therefore, we suggest that the efficacy of administration of steroids in this situation should be explored.

\section{Declarations}

Conflict of interest The authors declare no competing interests.

\section{References}

Doser AK, Hartmann K, Fleisch F, Kuhn M (2002) Suspected neurological side-effects after tick-born encephalitis vaccination. Praxis (Bern 1994) 91:159-62. https://doi.org/10.1024/0369-8394.91.5. 159

Fenichel GM (1982) Neurological complications of immunization. Ann Neurol 12:119-28. https://doi.org/10.1002/ANA.410120202

Havla J, Schultz Y, Zimmermann H, Hohlfeld R, Danek A, Kümpfel $T$ (2021) First manifestation of multiple sclerosis after immunization with the Pfizer-BioNTech COVID-19 vaccine. J Neurol 11:1-4. https://doi.org/10.1007/S00415-021-10648-W

Headache Classification Committee of the International Headache Society (IHS) The International Classification of Headache Disorders (2018) 3rd edition. Cephalalgia 38:1-211. https://doi.org/10.1177/ 0333102417738202

Jackson LA, Anderson EJ, Rouphael NG, Roberts PC, Makhene M, Coler RN et al (2020) An mRNA vaccine against SARS-CoV-2 — preliminary report. N Engl J Med 12(383):1920-1931. https:// doi.org/10.1056/NEJMoa2022483

Khayat-Khoei M, Bhattacharyya S, Katz J, Harrison D, Tauhid S, Bruso $P$ et al (2021) COVID-19 mRNA vaccination leading to CNS inflammation: a case series. J Neurol 1:1-14. https://doi.org/ 10.1007/S00415-021-10780-7

Molina-Gil J, González-Fernández L, García-Cabo C (2021) Trigeminal neuralgia as the sole neurological manifestation of COVID-19: a case report Headache. 61:560-562. https://doi.org/10.1111/head.14075

Narasimhalu K, Lee WC, Salkade PR, De SDA (2021) Trigeminal and cervical radiculitis after tozinameran vaccination against COVID-19. BMJ Case Reports 14:e242344. https://doi.org/10. 1136/BCR-2021-242344

Polack FP, Thomas SJ, Kitchin N, Absalon J, Gurtman A, Lockhart S, et al (2020) Safety and efficacy of the BNT162b2 mRNA Covid19 vaccine. N Engl J Med 383:2603-2615. https://doi.org/10. 1056/NEJMoa2034577

Trigeminal neuralgia (2021) https://www.uptodate.com/contents/ trigeminal-neuralgia $?$ search $=$ trigeminalneuralgia $\&$ source $=$ search_result\&selectedTitle $=1 \sim 150 \&$ usage_type $=$ default $\&$ display_rank=1 (accessed 12 SEPT 2021)

Wan EYF, Chui CSL, Lai FTT, Chan EWY, Li X, Yan VKC et al (2021) Bell's palsy following vaccination with mRNA (BNT162b2) and inactivated (CoronaVac) SARS-CoV-2 vaccines: a case series and nested case-control study. Lancet Infect Dis S1473-3099(21):0045100455. https://doi.org/10.1016/S1473-3099(21)00451-5

Publisher's Note Springer Nature remains neutral with regard to jurisdictional claims in published maps and institutional affiliations. 